\title{
LA ARBORICULTURA Y EL COOPERATIVISMO AGRARIO EN EL SECANO DE LA MONTAÑA (COMARCA DE ALCOI)
}

\author{
José Costa Mas
}

Los valles y corredores del espacio montañoso situado al interior de la provincia alicantina han sido tradicionales dominios de una agricultura de secano, de débiles y aleatorios rendimientos, pero, como respuesta, han cuajado excelentes logros en el plano de la industrialización. Ésta fue más temprana en Les Valls d'Alcoi, donde ya en el setecientos al espacio rural se insertó en el putting-out system emanado desde el foco alcoyano. Con el tiempo, éste ha polarizado hombres y funciones, convirtiéndose -secundado por Cocentaina y Muro- en «centro» de una «periferia» formada por una constelación de pequeñas entidades dependientes, con las que guarda estrechas relaciones, bien por difusión de actividades -entre ellas las sumergidas-, bien por desplazamiento pendular de activos rurales hacia aquél.

Es cierto que la dominación urbano-industrial se ha traducido en una continua leva de la población rural (de los 27 municipios comarcales, en 1970-81 fueron regresivos 22 y la mitad de ellos perdieron entre el $25 \%$ y el $56 \%$ de sus efectivos), pero en gran medida tal leva atañe a los excedentes laborales que no puede absorber la agricultura comarcal, y ésta subsiste, en muchos casos, gracias al acervo de agricultores a tiempo parcial, a su vez propiciado por la simbiosis rural-urbana. A nuestro entender, el balance final no es tan desequilibrado como podría inferirse del éxodo rural: la actividad agraria de Les Valls ha encontrado en la industria, más que un sustituto, el complemento indispensable.

Un éxodo de tal envergadura, unido a la escasez de tiempo del alternante, han desatado, eso sí, un insidioso abandono de las tierras marginales, que se han ido sumando a los, de entrada, cuantiosos espacios incultos (el 90\% de la extensión comarcal), con la amenaza que ello supone para todo un paisaje (el de las graderías, las más altas, de bancales, los más estrechos). 
Pero en la calidad del paisaje humanizado, no sólo cuenta la mera presencia del hombre -la densidad demográfica-, sino también su volición e iniciativa para obtener provecho del medio y de los medios puestos a su alcance. Y el agricultor de Les Valls no las ha escatimado (y menos el de completa dedicación o de tipo familiar); a pesar de las contrariedades físicas, más acentuadas en área de montaña, ha ido mutando el paisaje agrario, el cual, aunque con cierta inercia, se nos presenta en cada etapa como una respuesta humana a situaciones en evolución permanente.

$\mathrm{Al}$ respecto, si nos remitimos a un período largo, como el transcurrido desde 1912, las transformaciones experimentadas por el campo comarcal han sido de tal amplitud que, como muestra, basta comparar el aprovechamiento de la tierra en aquella fecha, cuando imperaba la clásica trilogía mediterránea (44\% de viñedos, $41 \%$ para la cerealicultura y $12,5 \%$ de olivar), con la situación actual reflejada en la tabla I.

La dinámica de cambio no pasa más desapercibida durante las últimas dos décadas, sobre un tiempo, pues, mucho más breve (bien es verdad que coinciden, probablemente, con una aceleración rítmica en la evolución de las condiciones de principios de siglo). En efecto desde $1965 \mathrm{ca}$. el antedicho repliegue «en horizontal» (contracción del terrazgo por abandono de laderas), es compensado por un crecimiento «en vertical» que adopta tres facetas: una, el avance del árbol -con su imagen alusiva de verticalidad- sobre los aprovechamientos extensivos del suelo; otra, la intensificación de las explotaciones, merced a la progresión de ciertos frutales y a la atención cultural que se dispensa al antaño descuidado olivar; y la tercera, la potenciación experimentada por las asociaciones de agricultores para la defensa comercial de ciertos productos.

En un artículo anterior (COSTA, 1985) se analizaron las estructuras agrarias (las explotaciones y su tipología) de Les Valls d'Alcoi. El presente estudio lo planteamos, a efectos expositivos, en dos partes: la primera versa sobre los diferentes cultivos arbóreos de esta comarca del secano montañoso del norte de la provincia y en la siguiente se aborda el tema de la comercialización de las producciones de dicha arboricultura, con especial hincapié en la problemática del cooperativismo agrario.

\section{LOS CULTIVOS ARBÓREOS}

En el secular y progresivo proceso de arborización que han experimentado los secanos de la casi totalidad del País Valenciano, la agricultura de Les Valls d'Alcoi no es, en absoluto, una excepción, y ello la ha conducido a la siguiente distribución de los aprovechamientos del suelo: 


\section{TABLA I}

Superficies ocupadas por los cultivos, en Ha.

\begin{tabular}{|c|c|c|c|c|}
\hline Cultivos (*) & Secano & $\underline{\text { Regadío }}$ & Total & $\%$ \\
\hline Olivo & 8.818 & 44 & 8.862 & 46,79 \\
\hline Almendro & 3.984 & 9 & 3.993 & 21,08 \\
\hline Frutales & 3.392 & 313 & 3.705 & 19,57 \\
\hline Otros herbáceos & 308 & $\underline{346}$ & 654 & 3,46 \\
\hline Total ......... & 18.201 & 737 & 18.938 & 100,00 \\
\hline
\end{tabular}

Fuente: Ministerio de Agricultura, hojas 1-T año 1983. Elaboración propia.

(*) En los arbóreos sólo se reflejan las extensiones en plantación regular y en los herbáceos las de ocupación primaria o principal.

El predominio de la arboricultura es abrumador: más del 87\% de las cerca de $19.000 \mathrm{Ha}$ que ocupan los cultivos. Por lo común, las explotaciones agrarias suelen practicar un policultivo entre las diferentes parcelas (más que catastrales, morfológicas); una práctica consuetudinaria, invalidada sólo en fechas recientes, ha sido la mixtificación cultural sobre un mismo predio. Dada la naturaleza quebrada de los terrenos, salvo en reducidas porciones de fondo de valle, las plantaciones -y las sembraduras- se disponen según un sistema generalizado de aterrazamientos en gradería.

En los epígrafes siguientes se exponen las principales características que presentan los cultivos arbóreos en la actualidad y su evolución más reciente. Aunque referimos en primer lugar los más extendidos -olivo y almendro-, se dedica particular atención a la fruticultura de producción carnosa (manzano, melocotonero, cerezo) que, siendo exclusiva -fuera, claro es, del regadío- de los secanos húmedos de montaña, constituye uno de los rasgos más sobresalientes de la agricultura de Les Valls.

Mientras que olivares y almendrales muestran una considerable ubicuidad a escala comarcal, cada uno de dichos frutales ha propendido a un asiento selectivo sobre una determinada subcomarca, bien que, tomados globalmente, aparecen representados por casi todo el territorio.

\section{El olivo}

Es el cultivo de mayor difusión y el más tradicional entre los arbóreos. En tiempos de Cavanilles la comarca producía unas 57.800 arrobas de aceite al año. A partir de la filoxeración del viñedo el olivar cobró incremento, aunque hacia 1912 todavía cubría poco menos de 3.000 $\mathrm{Ha}$, el 10,2\% de la extensión cultivada. En 1950 superaba con creces las $9.000 \mathrm{Ha}(35 \%$ del olivar provincial), de las que 200 eran de regadío y 300 en asociación con otros cultivos. 
La durísima helada de 1956, que produjo graves quebrantos, marcó el fin de su progresión. Le sucedió una prolongada decadencia, presidida por los precios poco remuneradores del aceite, los estragos causados por la mosca blanca y el progresivo encarecimiento y escasez de la mano de obra necesaria para la recolección.

Los árboles más resentidos por la helada se arrancaron, pero el proceso de sustitución fue bastante limitado, pues lo restringían las condiciones climáticas y topográficas sobre las que descansaba una parte considerable del olivar; además, muchas plantaciones comenzaban a entrar en producción y la longevidad del olivo favorecía un compás de espera, sobre todo en el marco de la agricultura a tiempo parcial (los agricultores alternantes casi se limitaban a recoger la aceituna y transportarla a la almazara).

De ahí que la coyuntura recesiva, que ha arrastrado la oleicultura comarcal durante más de dos décadas, no se tradujera en una reducción paralela de la superficie del olivar, que apenas pierde un 3\% en 1950-1983.

Hasta finales de los setenta todos los testimonios coinciden en señalar que la importancia del olivar comarcal no respondía a la extensión de las plantaciones, que en gran parte asumían una condición meramente residual. El esplendor de la época autárquica era sólo un recuerdo; apenas se abonaba y se desatendían los cuidados; la mengua de producción, la exigüidad del beneficio y las desatenciones conformaban a modo de un círculo vicioso.

Con todo el olivar seguía presente, casi incólume, a la espera de mejor coyuntura. Ésta, si bien se inició tímida y efímeramente al subir la cotización del aceite en 1974, se hizo plena realidad en 1981, al coincidir una fuerte apreciación del mismo con lo que se llamó «cosecha del siglo» de la aceituna, a la cual se sumó un récord de rendimiento (del $26 \%$ al $27 \%$ de aceite, cuando la media solía ser del 23\%) que fue favorecido por la indigencia pluviométrica de ese año.

A este alza de precios se ha unido una comercialización asegurada en virtud de que la aceituna comarcal ha interesado -crecientemente desde 1970- al empresariado catalán del ramo oleícola. Todo ello, unido al menor riesgo relativo de heladas, hace que el olivo sea hoy uno de los cultivos que confieren mayores garantías de seguridad al agricultor.

En consecuencia, existe un renovado interés por él. Se labora, se abona y se poda mejor. El vareo y la recogida del fruto caído han sido sustituidos por el sistema de ordeño, practicado a su justo tiempo, cuando la aceituna entra en sazón, lo cual es posible gracias a que en ese quehacer intervienen todas las ayudas familiares; ello proporciona una mayor calidad al aceite.

Hoy los olivares presentan un excelente aspecto vegetativo y sanitario. Por todas partes se observa un proceso de renovación del arbolado mediante la práctica del reinjerto y de la poda de regeneración, e incluso replantaciones (acogidas al plan de reestructuración del olivar). La presencia de viveros de olivos en la huerta de Beniarrés atestigua la bonanza que atraviesa el sector. 
Con todo, no faltan los problemas, tales como la clásica vecería y los ataques de repilo, cochinilla, mosca, etc., así como los obstáculos de la topografía frente a la mecanización y lo trabajosa que es la recolección (en jornales puede suponer el $40 \%$ y $50 \%$ del producto bruto). Pero los mayores problemas son quizás los de orden comercial y su remedio pasa por el perfeccionamiento de cooperativismo.

\section{TABLA II}

Distribución del olivar, en Ha.

\begin{tabular}{l}
\multicolumn{1}{c}{ Subcomarcas } \\
\hline Foia d'Alcoi \\
El Comtat \\
La Valleta d'Agres \\
Vall de Perputxent \\
Zona centro-norte \\
Vall de Planes \\
Vall de Seta \\
Vall de Travadell \\
Vall de Penàguila \\
Zona oriental
\end{tabular}

COMARCA

\begin{tabular}{r}
$H a$. \\
\hline 625 \\
2.713 \\
579 \\
823
\end{tabular}

4.740 777 1.174

626

1.542

$\mathbf{4 . 1 2 2}$

8.862

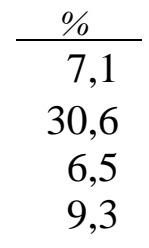

$\mathbf{5 3 , 5}$

8,8

13,2

7,1

17,4

46,5

100,0

Fuente: Ministerio de Agricultura, 1983.

Las principales variedades cultivadas -autóctonas o afincadas de muy antiguo- son la mansanella y la blanqueta; ambas proporcionan un aceite de calidad. Mucha menor presencia tienen la alfafarenca, que está en plena regresión, y la genoveva o beniaia.

Los marcos más usuales de plantación son 9x9 y 10x10 m. En año bueno se obtienen de 15 a $18 \mathrm{~kg}$ de fruto por pie, pero a causa de la fuerte vecería el promedio no pasa de $10 \mathrm{~kg}$, o sea más de $800 \mathrm{~kg} / \mathrm{Ha}$ (superando a las otras zonas olivareras de la provincia).

La mayor parte de la cosecha, con mucho, se destina a la producción de aceite, con un rendimiento en peso del $23 \%$ al $26 \%$ y excelentes condiciones físico-químicas y organolépticas (hasta el $70 \%$ del aceite queda por debajo de $0^{\prime} 5^{\circ}$ de acidez y un $20 \%$ en 0 ' $5^{\circ}$ y $1^{\circ}$ ).

\section{El almendro}

A diferencia del olivo, no es cultivo de gran tradición en la comarca, la 


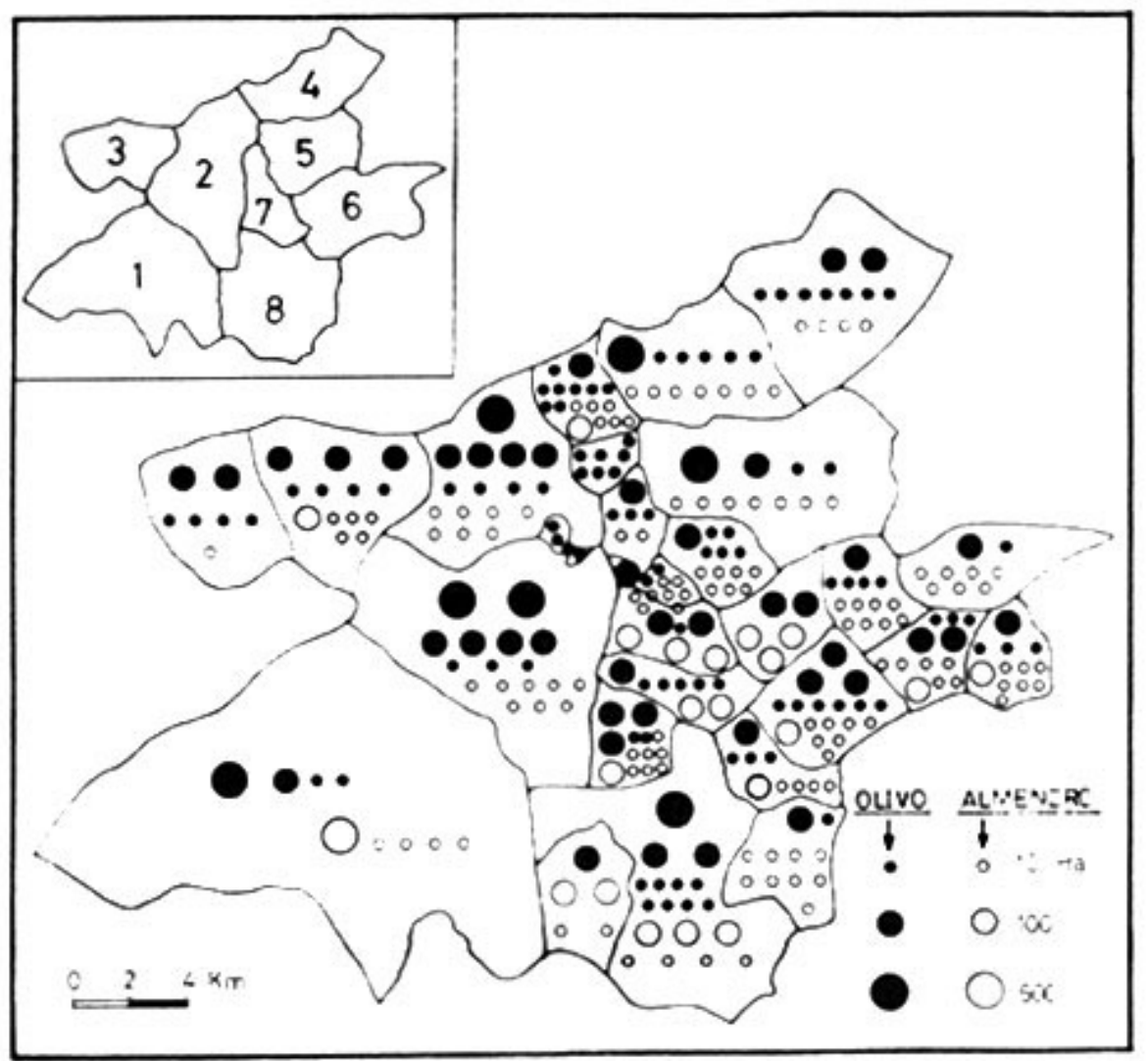

FIGURA 1. Distribución de las superficies de olivo y almendro. En el recuadro superior, las subcomarcas de Les Valls d'Alcoi: 1, La Foia d'Alcoi; 2, El Comtat; 3, La Valleta d'Agres; 4,La Vall Perputxen; 5, La Vall de Planes; 6, La Vall de Seta; 7, La Vall de Travadell; 8, La Vall de Penàguila.

cual viene a ser una zona ecológica límite para el almendro. Ni Cavanilles ni Madoz lo mencionan. En la segunda década del siglo actual apenas había una quincena de hectáreas. Al parecer sólo empezó a cobrar cierto auge una vez mediada la centuria. Lo cierto es que en la segunda mitad de los sesenta y principios de los setenta se difundió por casi toda la comarca (a menudo indiscriminadamente, sin contar los riesgos climatológicos). Su expansión notable, casi sorprendente, que respondía a las esperanzas depositadas en unos precios en alza y en la adopción de variedades nuevas, de floración tardía, lo situó como segundo cultivo comarcal en cuanto a superficie. Posteriormente, patentizadas las duras restricciones térmicas, el ritmo de plantación se ha ralentizado. 
TABLA III

Distribución del almendro (plantaciones regulares, en Ha.)

\begin{tabular}{l}
\multicolumn{1}{c}{ Subcomarcas } \\
\hline Foia d'Alcoi \\
El Comtat \\
La Valleta d'Agres \\
Vall de Perputxent \\
Zona centro-norte \\
Vall de Planes \\
Vall de Seta \\
Vall de Travadell \\
Vall de Penàguila
\end{tabular}

COMARCA

\begin{tabular}{l}
$H a$ \\
\hline 545 \\
317 \\
172 \\
111
\end{tabular}

$\mathbf{1 . 1 4 5}$

146

956

591

1.155

4.122

3.993

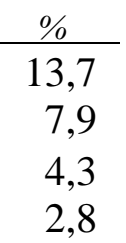

$\mathbf{2 8 , 7}$

3,7

23,9

14,8

28,9

46,5

100,0

Fuente: Ministerio de Agricultura, 1983.

Ocupa unas 4.000 Ha en plantación regular (21\% de la superficie cultivada), aparte de un considerable número de pies diseminados. En contraste con el olivar, las mayores densidades de almendro se hallan en la zona oriental, donde encuentra terrenos $\mathrm{y}$, sobre todo, microclimas más adecuados. La zona centro-norte, abundante en hoyas y depresiones, es más reacia a este cultivo, que en ella se circunscribe a áreas con cierta benignidad térmica, como la formada por las vertientes de la sierra de Benicadell en los términos de Muro, Gayanes y Beniarrés.

Muchas plantaciones se desarrollan en condiciones de gran marginalidad; tan sólo escogiendo los emplazamientos térmicamente más favorables puede vegetar con garantías de éxito. Frecuentes y drásticas pérdidas de cosecha a causa de las heladas hacen de ésta una «tierra de almendros, pero no de almendras», según el agricultor de Les Valls.

¿Cómo explicar, pues, su singular propagación? Aparte de que es un árbol poco exigente en suelo y agua, su aceptación descansa en el carácter complementario que asumen las rentas agrarias en gran parte de la comarca; el descenso de la población activa y la elevación de los salarios agrícolas incentivaron las plantaciones en atención a la escasa mano de obra requerida para el mantenimiento de un arbolado de cómodo cultivo, que encaja perfectamente con la agricultura a tiempo parcial.

Alrededor de dos tercios de las plantaciones son de variedad marcona, cuya gran calidad y buen precio suele compensar su susceptibilidad a las heladas. Otras variedades tradicionales son la touera y las comunas, que suponen en torno al $10 \%$ y $5 \%$ de la superficie, respectivamente. A partir de los años sesenta se difundieron las de tipo desmayo por ser de floración tardía (y por 
emplearse como polinizadoras en las plantaciones nuevas de marcona), las cuales representan hoy una quinta parte de los almendrales.

Los marcos de plantación oscilan mucho; los más generalizados dan densidades de 170 a 180 árboles/Ha, con tendencia a la densificación. Los rendimientos, mucho más fluctuantes, se estiman, para un año sin heladas sensibles, en cerca de $600 \mathrm{~kg} / \mathrm{Ha}$ de almendra en cáscara.

Aunque es muy minoritario, cabe señalar la presencia de medio centenar de hectáreas de otro árbol productor de frutos secos, el nogal, que se adapta bien a las condiciones físicas de la zona.

\section{La nueva fruticultura de los secanos húmedos}

Aunque el cultivo de árboles productores de frutas carnosas estuvo mucho tiempo limitado al autoconsumo o, como mucho, a la colocación de pequeños excedentes en la propia comarca, hoy se puede afirmar que uno de los fenómenos más importantes de la agricultura de Les Valls, junto a la expansión del almendro y la revalorización actual del olivar, es la gran difusión e importancia socioeconómica que, en los últimos tres lustros, han cobrado los frutales de pepita y de hueso, los cuales conforman hoy el auténtico «sector de vanguardia» de la agricultura comarcal.

El notable despegue que, a ritmo creciente en el curso de los últimos 20 años, ha conocido la mayor parte de esos frutales se ha visto favorecido por su mayor rentabilidad respecto a los otros aprovechamientos del secano, así como a su feliz adaptación a los suelos y en especial al clima de Les Valls, pues en una proporción del $92 \%$ se cultivan en sus secanos, que cabe caracterizar como «húmedos» dada la existencia de una abundante pluviometría, en general por encima de los $500 \mathrm{~mm}$, y un déficit hídrico que nunca se prolonga más de dos meses.

Se trata de frutales de producción carnosa, repartidos casi por igual entre las especies de hueso y las de pepita, cuya superficie global casi iguala la del almendro, al que la superan en trascendencia económica y social. El más extendido entre ellos es el manzano (39\%), pero hoy está en clara regresión, mientras que el melocotonero (28\%) y, sobre todo, el cerezo son de signo progresivo; también parece serlo, en menor medida, el ciruelo, aunque éste, al igual que el peral y albaricoquero (que van en retroceso), se cultivan en escasa cuantía.

Esta relativamente nueva fruticultura ha supuesto, allí donde se implantó, una intensificación de la agricultura comarcal, tradicionalmente dominada por cultivos más extensivos. La difusión del frutal marca el carácter progresivo de ciertas zonas con espíritu innovador. 


\section{TABLA IV}

Superficies de frutales en plantación regular, en Ha.

\begin{tabular}{|c|c|c|c|c|c|c|c|c|}
\hline $\begin{array}{l}\text { Subcomarcas } \\
\text { Total }\end{array}$ & $\underline{\text { manzano }}$ & Melocot. & Cerezo & Ciruelo & Peral & \multicolumn{2}{|c|}{ Albaricoq. } & tros \\
\hline 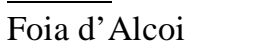 & 448 & 34 & 1 & 53 & 15 & 12 & _ & 563 \\
\hline El Comtat & 150 & 158 & 27 & 37 & 63 & 96 & 43 & 574 \\
\hline La Valleta & 428 & 91 & 4 & 36 & 60 & 3 & 5 & 627 \\
\hline Perputxent & 41 & 25 & 26 & 12 & 8 & 10 & 105 & 227 \\
\hline Zona centro-norte & 1.067 & 308 & 58 & 138 & 146 & 121 & 153 & 1.991 \\
\hline Planes & 56 & 34 & 239 & 13 & 6 & 39 & - & 387 \\
\hline Seta & 38 & 209 & 20 & 1 & 11 & 1 & - & 280 \\
\hline Travadell & 47 & 350 & 66 & 39 & 8 & 23 & 3 & 536 \\
\hline Penàguila & 241 & 162 & 15 & 50 & 32 & 11 & - & 511 \\
\hline Zona oriental & 382 & 755 & 340 & 103 & 57 & 74 & 3 & 1.714 \\
\hline COMARCA & 1.149 & 1.063 & 398 & 241 & 203 & 195 & 156 & 3.705 \\
\hline$\%$ del total & 39,1 & 28,6 & 10,8 & 6,5 & 5,5 & 5,3 & 4,2 & 100,0 \\
\hline
\end{tabular}

Fuente: Ministerio de Agricultura, 1983. Elaboración propia.

En determinados espacios de Les Valls es patente una especialización o «vocación» frutícola, lo que ha dado pie a caracterizar como «subcomarca del manzano» a la Valleta d'Agres, «del melocotonero» a la Vall de Travadell (y parte de Seta) y «del cerezo» a la Vall de Planes. Más adelante se comentará esta peculiar distribución que, aunque pueda parecer paradójico, coexiste con el secular arraigo del policultivo y aun con la mixtificación de cultivos.

Asimismo, es manifiesto que la adscripción de la fruticultura a los grandes tipos de explotaciones agrarias de Les Valls es de signo muy diverso, como lo es su significación social. En efecto, por su carácter trabajoso, casi artesanal, varios de estos frutales estaban predestinados a desenvolverse en el seno de la agricultura de tipo familiar, y así ha sido, puesto que dos de los más representativos, el cerezo y el melocotonero se desenvuelven preferentemente en ese tipo de explotaciones. Aunque por «efecto demostración», al revelarse como cultivo rentable, también los asumieron algunos propietarios alternantes, la gran mayoría de éstos han rehusado hacerlo debido a que tales frutales exigen un perfil temporal de dedicación que no se acomoda al de sus quehaceres externos a la explotación. Por último, bajo cierto proceso de tecnificación, el manzano y los frutales minoritarios se adscriben singularmente a los masos y explotaciones de signo más empresarial, en plantaciones de relativa envergadura.

A continuación se exponen los principales rasgos que presentan los tres cultivos frutícolas más caracterizados, que son, por orden de extensión, el manzano, el melocotonero y el cerezo.

El manzano.- De todos los frutales antes referidos, el manzano es el de mayor difusión, ocupando 1.449 Ha (apenas un $12 \%$ en regadío). Su presen- 
cia es mayor en la zona centro-norte $(73,6 \%$ del total), coincidiendo con las áreas donde más representación tienen las propiedades dilatadas. Si por superficie absoluta destaca en la Foia d'Alcoi, es la Valleta d'Agres la que ofrece una mayor densidad de este arbolado, por lo cual se la ha bautizado como «subcomarca del manzano», y en tercera posición figura el término de Penàguila. Precisamente los tres espacios se caracterizan por una considerable presencia de masos y masets, en los que las plantaciones de manzanos, siempre de cierta amplitud, respondieron a inversiones de extracción urbana y a un enfoque empresarial y rentabilista de la explotación (vide COSTA, pp. 95-97); además, esa específica vocación frutícola de los masos tiene una concausa de tipo climático, pues la mayoría de ellos se encuentran en zonas húmedas y frescas, incluso caracterizadamente frías, por lo cual entre la gama de frutales el que mejor se adapta es el manzano (también el ciruelo, que en algún mas opera como sustituto de los almendros marginales).

No por ello está excluida su existencia en explotaciones de tipo familiar, pero se da en escala mucho menor, a excepción de algunos puntos concretos, p. ej., del Comtat, en donde el manzano de regadío casi iguala en extensión al de secano.

\section{TABLA V}

Superficies de manzanos por años de plantación regular, en Ha.

\begin{tabular}{|c|c|c|c|c|c|c|}
\hline Subcomarcas & $1978-83$ & $1975-77$ & $1973-74$ & $1968-72$ & $1963-67$ & Anterior \\
\hline Foia d'Alcoi & 64,9 & 20,8 & 47,3 & 192,6 & 84,3 & 37,7 \\
\hline La Valleta & 51,9 & 40,9 & 62,2 & 197,9 & 64,5 & 10,1 \\
\hline Comtat-Perputxent & 16,91 & 10,9 & 21,7 & 89,2 & 34,4 & 6,0 \\
\hline Zona centro-norte & 133,7 & 72,6 & 131,2 & 479,7 & 181,2 & 53,8 \\
\hline Vall de Penàguila & 5,2 & 19,0 & 12,9 & 98,5 & 60,4 & 43,7 \\
\hline Otras áreas & 25,0 & 4,8 & 18,9 & 54,3 & 19,0 & 6,7 \\
\hline Zona oriental & 30,2 & 23,8 & 31,8 & 152,8 & 89,4 & 50,4 \\
\hline COMARCA & 163,9 & 96,4 & 163,0 & 632,0 & 270,6 & 104,2 \\
\hline
\end{tabular}

Fuente: Ministerio de Agricultura, Inventario de frutales (datos municipales), 1977. Elaboración propia.

De la tabla precedente se excluyen 18,4 Ha de edad ignorada. La primera columna expresa la diferencia entre las superficies de 1983 y las del inventario; tiene un valor meramente indicativo, pues se desconocen las plantaciones que fueron arrancadas en ese intervalo.

Los datos del inventario demuestran que si bien el manzano ya estaba presente con anterioridad, fue en los años centrales de la década de los sesenta cuando empieza a cobrar cierta relevancia, para alcanzar su pleno apogeo en el quinquenio 1968-72 que concentra prácticamente la mitad de las plantacio- 
nes existentes en la fecha del inventario, registrando un promedio de 126,5 nuevas Ha por año. Desde entonces el ritmo de plantaciones ha sido cada vez menor; en 1973-74 todavía se registró una media anual de 81,5 Ha, pero en 1975-77 se redujo a tan sólo $32 \mathrm{Ha}$. Después la desaceleración se acentúa, de forma que en 1983, según las Cámaras Agrarias, los manzanos que no habían entrado aún en producción apenas suponían 21 Ha. Es más, en los últimos años se han arrancado muchas plantaciones en edad de producir por las pérdidas económicas que acarreaban.

Su cultivo se basó inicialmente en ciertas variedades autóctonas de la montaña húmeda alicantina, entre ellas la roja de Beneixama y la perelló. Pero en la década de los sesenta se impusieron las variedades americanas, del tipo delicias, las cuales mostraron una buena adaptación al medio y, con ello, una aceptable producción en año normal si se tiene en cuenta que se desenvuelven en terrenos de secano. A tenor de inventario de 1977 nada menos que el $84,9 \%$ de las plantaciones son de variedad delicia, descollando la red relicious, con el 56,8\%, seguida a distancia por la golden $(20,5 \%)$ y la starking $(7,6 \%)$. Fuera de este grupo sólo merece mención la cirio $(6,2 \%)$.

El manzano de les Valls se planta siempre en vaso, dispuesto a todo viento y en marco real de $6 \times 6 \mathrm{~m}$ o de 7x7 m (unos 200 árboles/Ha). Los pies más utilizados son el franco y el clonal EM II. Su longevidad es de unos 30 años, con tres de formación y plena producción a partir del séptimo año, pudiendo oscilar entonces su rendimiento entre 12.000 y $18.000 \mathrm{Kg} / \mathrm{Ha}$, a una media de $15.300 \mathrm{~kg} / \mathrm{Ha}$ (unos $75 \mathrm{~kg}$ por árbol) en año normal. Sufre diversas fisiopatías (mal blanc, bitter, pitt, etc.) y la sequía puede provocar la mengua del calibre, pero el problema más grave han sido las pérdidas causadas por el pedrisco. La explotación requiere considerables gastos, entre los que sobresalen los abonos e insecticidas y fungicidas, cuyos precios se han disparado en los últimos años.

Su cultivo atraviesa una crítica situación, cuyas causas ya se analizaron anteriormente (vide COSTA, pp. 97-98).

El melocotonero.- Ha cobrado mayor amplitud en la zona oriental ( $71 \%$ del total), sobre todo en les Valls de Travadell y de Seta $(52,6 \%)$ donde destacan Gorga, con más de 200 Ha, Quatretondeta, con 148 Ha y Benimarfull que alcanza cerca del centenar.

Este frutal se cultivaba de antiguo en dichos valles, usualmente en pies destinados para autoconsumo. A mediados de la década de los sesenta se iniciaron en Gorga las plantaciones regulares, cuyos buenos resultados alentaron las inversiones que conocieron un auténtico boom en 1968-72 (tal como ocurriera en toda la fruticultura comarcal). A tenor del inventario la cadencia de las plantaciones remitió en 1973-77, quizá a consecuencia del sobreesfuerzo inversor de la etapa precedente.

En los últimos años parece haberse recuperado el ritmo; si en 1971 su cultivo cubría 436 Ha, en 1977 ocupaba 736 y en 1983 se extendía sobre $1.063 \mathrm{Ha}$, con ganancias de unas $300 \mathrm{Ha}$ durante cada intervalo. 


\section{TABLA VI}

Superficies de melocotoneros por años de plantación regular, en Ha.

\begin{tabular}{|c|c|c|c|c|c|c|}
\hline Subcomarcas & $1978-83$ & $1975-77$ & $1973-74$ & $1968-72$ & $1963-67$ & Anterior \\
\hline Vall de Travadell & 125,2 & 31,1 & 24,1 & 149,5 & 18,6 & 0,5 \\
\hline Vall de Seta & 60,8 & 4,4 & 6,2 & 135,5 & 10,8 & 0,7 \\
\hline Vall de Penàguila & 64,4 & 11,1 & 19,0 & 36,0 & 25,4 & 4,3 \\
\hline El Comtat & 11,3 & 21,7 & 23,4 & 81,0 & 15,1 & 3,1 \\
\hline La Valleta & 22,6 & 11,6 & 5,8 & 46,2 & 3,8 & 0,2 \\
\hline Otras áreas & 15,1 & 4,2 & 9,7 & 60,6 & 1,1 & 0,9 \\
\hline COMARCA & 163,9 & 84,1 & 88,2 & 506,8 & 74,8 & 9,7 \\
\hline
\end{tabular}

Fuente: Inventario de frutales, 1977. Elaboración propia.

Nota: La primera columna responde al criterio expuesto a continuación de la tabla V.

Casi todo el melocotonero se cultiva en el secano húmedo, medio en el que halla reservas suficientes para soportar el verano y llevar el fruto a buen término cuando el otoño y ello gracias a unas variedades sui generis, al microclima y a unos suelos de textura francoarcillosa o arcillosa (con alto contenido en caliza). Con todo, la prolongada sequía de los últimos años se ha acusado en alguna campaña con la merma del calibre de la fruta.

Se estima que el $80 \%$ de sus plantaciones presentan un riesgo de solamente una helada cada cinco años, pues por su época de floración el melocotonero soslaya las heladas primaverales (no así la de abril de este año, excepcionalmente tardía y dura).

Antes de analizar su estructura varietal, conviene aludir a su peculiar forma de reproducción, pues contribuye a dar la razón de aquélla. En efecto, el patrón originario de la comarca es el «franco de melocotón» -en general procedente de variedades tardías- que se reproduce por semilla. Éste era antaño el único sistema: el árbol se obtenía directamente de la semilla, pues el patrón no se injertaba, lo cual desembocó en una enorme diversificación de variedades.

A primera vista el inconveniente era que, como cada variedad maduraba en distinta época, se multiplicaban las tareas de recolección. Pero en el pasado esto se trocaba en ventajas, pues aparte de que el salario agrícola era bajo, la cosecha se presentaba de forma muy escalonada, sin agobios, lo que a su vez favorecía la colocación de los excedentes en el mercado.

La mayor rémora que presentaba el sistema tradicional era que los árboles procedentes de patrón franco acusaban una resistencia más limitada a la sequía y a los suelos calizos, así como un detrimento en la calidad de la fruta.

Cuando creció la demanda, con mayores exigencias cualitativas, el fruticultor tuvo que replantear el sistema en atención al deseable incremento de unas cosechas a obtener en la época más idónea y con una mejora cualitativa. 
A principios de los setenta se empezaron a utilizar las semillas de híbridos de melocotonero y almendro para obtener nuevos tipos de patrones, los cuales, por cierto, evidenciaron una mayor resistencia a la clorosis.

Al mismo tiempo se difundió la práctica del injerto; el patrón híbrido pasó a injertarse con escudos de la variedad deseada, por lo común tardía. Pero pronto se pudo observar una falta de homogeneidad en la plantación, provocada por una deficiente afinidad entre patrón híbrido e injerto, $y$, a veces, una mengua cualitativa en la fruta; esto se acusaba tanto más cuanto mayor era la similitud morfológica entre el híbrido que proporcionaba la semilla y el almendro. La cuestión se solucionó seleccionando aquellos híbridos cuyos caracteres se asemejaran más al melocotonero. El INIA y Extensión Agraria vienen prestando atención técnica para aprovechar y mejorar el material genético autóctono, del que se infieren buenos resultados.

Aunque hoy se sigue reproduciendo por siembra, es más usual adquirir las plantas en viveros (pies de ciruelo San Julián y de un híbrido selecto de origen francés).

Lo antes expuesto explica el gran número de variedades existentes, en su mayoría de origen autóctono (casi todas ellas tardías) y no homologables con ninguna otra. Según el inventario de 1977, de las diez primeras en extensión (superan el 82\%) hay cuatro «sin denominación», dos de las cuales encabezan la larga lista ocupando, respectivamente, el 21,5\% y el $18,4 \%$ de la superficie plantada; la tercera es la brasileña (18\%), que madura en la segunda quincena de junio; las que siguen, lo hacen con porcentajes del $6 \%$ e inferiores.

En los años 1965-70 una serie de variedades americanas tempranas, como la cardinal (5,3\% en 1977), dixired (4,5\%), springtime, etc., fueron introducidas en la comarca originariamente en ciertas explotaciones bien capitalizadas, de tipo mas, y de inmediato se difundieron entre las de carácter familiar. Pero no dieron buen resultado, pues debido a las condiciones climáticas la maduración se retrasa respecto a otras áreas productoras, de modo que las frutas de variedad temprana que se obtienen en Les Valls no pueden competir en precocidad: llegan 10 ó 15 días más tarde que, p. ej., las de Albaida y La Safor, ya con poco mercado para ellas y con el inconveniente añadido que supone la blandura de su pulpa.

En consecuencia, la generalidad de los fruticultores se inclinaron de nuevo hacia las tradicionales variedades tardías autóctonas, las cuales ofrecen un balance positivo, y más cuando la práctica del injerto, antes mencionada, está permitiendo una adecuada selección varietal que, a su vez, repercute en incrementos cuantitativos y cualitativos de las producciones (por otra parte más homogeneizadas).

Esas variedades autóctonas, cultivadas en secano, producen una fruta muy apreciada por sus condiciones organolépticas y, por añadidura, más dura y transportable. Ello propicia unos precios remuneradores.

Con todo, en los últimos años se observa una renovada tendencia hacia 
las clases tempranas, pero localizada sólo en Benimarfull, donde la singularidad climática propicia una maduración más precoz, anticipada unos diez días respecto a la zona de Gorga y Seta.

Atendiendo al tiempo de recolección, las cosechas de melocotón se pueden catalogar en tres grupos: tempranas, agostenques y tardanes; las primeras se dan en junio y julio, las segundas en agosto, y las últimas entre el 15 de septiembre y finales de octubre, con pequeñas partidas que alcanzan hasta el 10 de noviembre.

La plantación recibe unas 5 ó 6 labores al año y los abonos y tratamientos adecuados. En esta zona de montaña, debido al clima, el melocotón sufre menos ataques de ceratitis, que pueden causar estragos en otras áreas. Aun así, es una especie muy afectada por problemas fitopatológicos (pulgón verde, fussicoccum, etc.), lo cual explica la incidencia de los tratamientos fitosanitarios que pueden suponer más de la quinta parte del costo de producción.

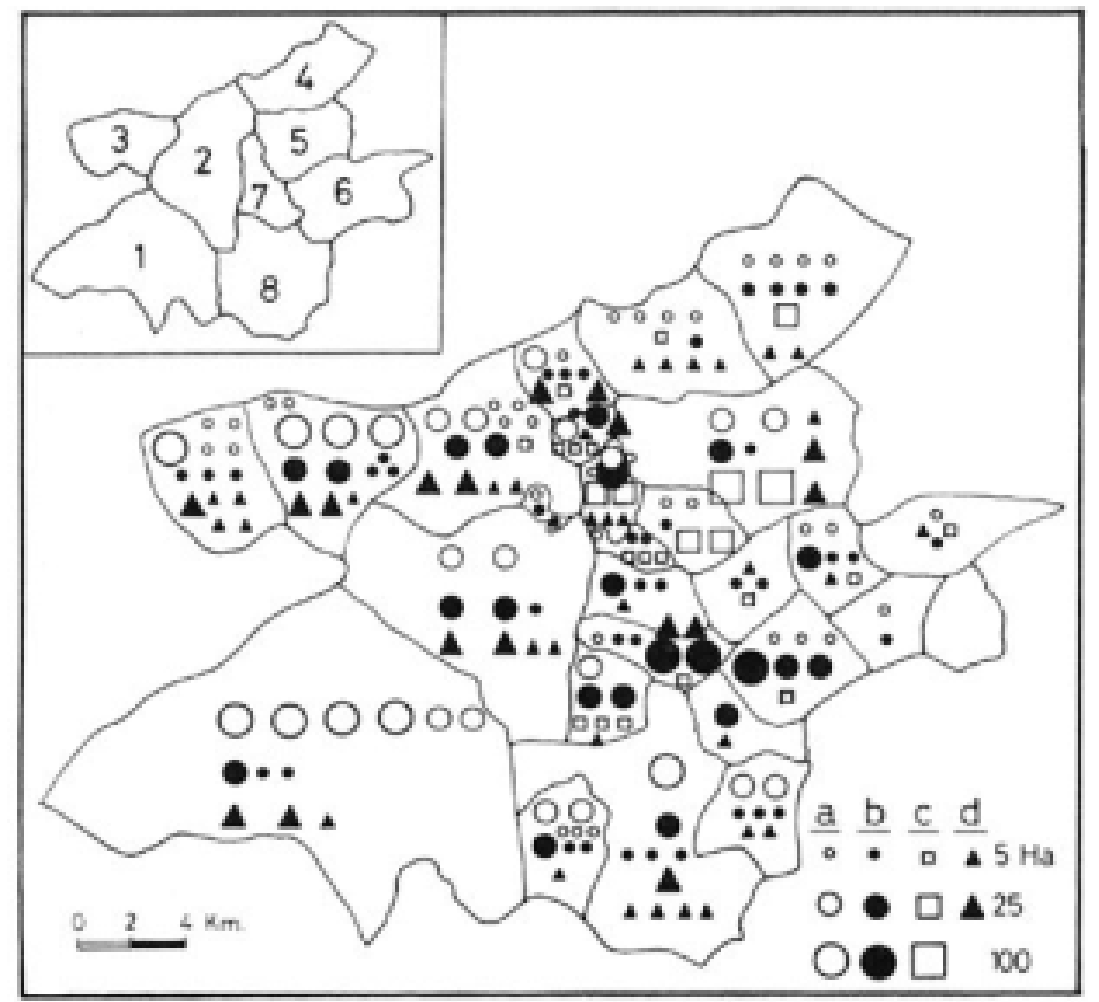

FIGURA 2. Distribución de las superficies de frutales. Leyenda; a, manzano; b, melocotonero; c, cerezo; d, ciruelo, peral y albaricoquero. 
El rendimiento viene a oscilar entre 13.000 y $15.000 \mathrm{~kg} / \mathrm{Ha}$. Para su recogida se estiman unos treinta jornales, ya que hay que escalonarla según madura el fruto.

El cerezo.- Una de las zonas cereceras más importantes a nivel español es la que se ubica en la parte oriental de Les Valls d'Alcoi y el área contigua del Marquesat de Dénia, la cual concentra casi la totalidad del millar de hectáreas de plantaciones regulares y de los 67.000 cerezos dispersos con que cuenta la provincia según datos oficiales de 1984 (quizá infraestimados), que dieron una producción de 3.300 Tm en esa fecha.

Se trata de una zona deprimida de montaña, sarpullida de diminutas localidades y con una base económica agraria, regida por el olivo, donde si bien el cerezo se cultivaba de antiguo, lo era de forma marginal en el marco de una economía de subsistencia.

En el presente, sin embargo, la cereza constituye un sector puntero de su agricultura, habiendo experimentado un auge notabilísimo, en particular durante la última década, sin duda merced a la consolidación de un cooperativismo que ha solucionado gran parte de los problemas de comercialización de esta fruta.

Su cultivo era conocido de antiguo; Cavanilles destacó la «muchísima cereza» que se producía en Planes. Sin embargo, hasta bien entrada la década de 1960 prácticamente sólo existía en forma de pies diseminados entre otros cultivos o alineados en los márgenes de los bancales y apenas se le dispensaban los cuidados mínimos. Es más, aunque por entonces comenzaban en Les Valls d'Alcoi las plantaciones regulares de cerezos y desde 1971 a 1983, según las cifras oficiales, éstas se incrementaron en un $150 \%$, el monto de los pies dispersos también aumentó al parecer un $80 \%$ en igual período. A primeros de los setenta éstos suponían un $60 \%$ o $70 \%$ de los cerezos censados, según cálculos de las Cámaras Agrarias, que en 1983 estiman en cerca de 51.000 los pies diseminados por la Vall de Planes, los cuales si estuvieran dispuestos en marco normal equivaldrían a una superficie mayor que la plantada con regularidad.

\section{TABLA VII}

Plantaciones, regulares o no, de cerezos según su edad, en Ha.

\begin{tabular}{|c|c|c|c|c|c|c|}
\hline Subcomarcas & $1978-83$ & $1975-77$ & 1973-74 & $1968-72$ & $1963-67$ & Anterior \\
\hline Planes & 32,6 & 37,8 & 250,1 & 22,2 & 7,7 & 350,6 \\
\hline Almudaina & 7,4 & 12,9 & 35,2 & 16,8 & 1,3 & 73,8 \\
\hline Benimarfull & 8,2 & 6,5 & 15,4 & 2,5 & - & 32,9 \\
\hline TOTAL & 48,2 & 57,2 & 290,7 & 41,5 & 9,5 & 457,3 \\
\hline
\end{tabular}

Fuente: Inventario de frutales, 1977. Elaboración propia.

Nota: Los tres primeros concentraban el $99,8 \%$ de los cerezos. No constan los de edad desconocida $(2,3 \%$ del total). 
A tenor del inventario, más del 63\% de los cerezos (incluyendo los pies dispersos) cultivados en aquella fecha databan del período 1968-72, que registró una media de 58,1 nuevas Ha por año, y en el quinquenio siguiente la superficie plantada creció alrededor del $30 \%$ (nos consta que ello coincidió con un generalizado proceso de reinjeto del arbolado antiguo). Durante la última década todo parece indicar que se ha producido una multitud de roturaciones para proceder a plantaciones intensivas. Los datos oficiales, que en 1983 cifran en unas $400 \mathrm{Ha}$ las plantadas en marco regular, quizá sean erróneos por defecto.

Con todo, su desarrollo tropieza con la limitación que impone la escasez de tierras adecuadas en estas áreas agrestes, pues el cerezo se vincula a microclimas especiales, instalándose en terrenos frescos y muy preferentemente sobre las terrazas o bancales de las laderas bien soleadas, donde la cosecha es más precoz. Pero en las últimas décadas se manifiesta, de forma progresiva y tanto en las plantaciones nuevas como en los reinjertos, una triple tendencia: hacia la concentración, lo que ha reducido las variedades a una decena (menos de dos tercios de las preexistentes), subsistiendo las más selectas y tipificadas; hacia las de producción temprana (francesa, tilagua), por su gran aceptación comercial y buenos precios; y también hacia ciertas clases tardías, las más duras y de mejor condición para el transporte (picotas). Como nítido reflejo de este proceso, la estructura de la producción ha mutado drásticamente en poco tiempo aunque las fuentes de información ofrecen datos contradictorios difícilmente contrastables, parece ser que en 1978 unos 3/4 del volumen cosechado en el conjunto del área cerecera de Alcoi-Dénia se extraía de variedades poco comerciales; por contra, en 1985 la situación se ha invertido, predominando ahora las cerezas de variedades selectas (ambrunesa, planera, tilagua, francesa, picota, etcétera).

Las nuevas plantaciones son de marco más denso, de $6 \times 6 \mathrm{~m}$ o 7x7 m, a todo viento (aunque se experimenta con la disposición en palmeta, a 4x5 m); se estructuran en líneas alternas de dos o más variedades, de floraciones simultáneas (a efectos de la polinización) y, a la vez, de recolección escalonada. Como los suelos son muy calizos se utiliza el patrón Santa Lucía, que da un menor vigor al árbol, con lo que la recolección es más cómoda y el marco se puede reducir en la medida que lo permita el frescor del suelo. Reciben 3 ó 4 labores, la primera más profunda y las otras superficiales. Se han difundido tácticas adecuadas de poda para que el árbol ramifique en horizontal y facilitar así la recogida de la cereza.

Si no se toman las medidas pertinentes, pueden causar problemas la mosca de la cereza, el cribado y el fussicoccum, así como los pájaros, pulgones y sobre todo el gusano cabezudo, cuyos ataques han sido favorecidos por la sequía.

Pero el problema que se presenta cada campaña de forma más acuciante es el de la recolección de la fruta, pues puede llegar a suponer el 800 lo de los gastos variables del cultivo. Todas las ayudas familiares (y personal contrata- 
do, si no bastan) participan en la recolección que se realiza «a pessiguets», cortando el pedúnculo con las uñas. La condición regresiva de la dinámica poblacional de la zona es una rémora para la deseable expansión de las plantaciones. En algunas de ellas ha llegado a perderse la fruta por concentrarse su maduración en escasos días; de ahí la conveniencia de escalonar las cosechas (lo que a su vez contribuye a la proliferación de variedades). La campaña cerecera, en términos globales, se extiende desde primeros de mayo hasta finales de julio.

\section{EL COOPERATIVISMO Y LA COMERCIALIZACIÓN}

En el contexto del País Valenciano las agrupaciones de agricultores para la comercialización en común están más desarrolladas, aunque todavía no alcanzan el nivel que es deseable, en los sectores de los cítricos y las hortalizas. Con todo, durante los últimos tiempos es perceptible cierta progresión del movimiento cooperativo (no exento de tradición y prestigio en algún caso, como el de la vinicultura) en determinadas áreas y producciones concretas del secano.

El cooperativismo de Les Valls d'Alcoi no ha sido una excepción, aunque presenta connotaciones específicas que se detallan en los siguientes subepígrafes. La mayoría de sus cooperativas agrarias se gestaron para la transformación de la aceituna de almazara; pero el fuerte letargo que atravesó la olivicultura comarcal, unido a la expansión de ciertos frutales, hizo que parte de aquéllas desviaran sus prestaciones hacia el mercado de frutas.

En suma, el asociacionismo ha incidido de forma particular sobre la aceituna y la cereza, que son precisamente las producciones agrarias que más singularizan a la zona de Alcoi, pues de todas las comarcas valencianas es la segunda en superficie olivarera y, con el área vecina de Dénia, la primera en cerezos. Sin duda, tal especialización y concentración geográfica es la que ha posibilitado que las pequeñas cooperativas locales preexistentes abordasen una política comercial conjunta, habiendo mejorado su operatividad al acogerse a ciertas adaptaciones institucionales en dos pasos: su concierto a finales de los setenta y, en fechas recientes, su constitución en cooperativas de $2 .^{\circ}$ grado. De éstas, la cerecera reúne la práctica totalidad de las minicooperativas del ramo y está gestando el tercer paso (a A.P.A.), pero de la oleícola se excluyeron las almazaras cooperativas más importantes.

Fuera de esos casos, también los productores de melocotón se han agrupado para el mercadeo conjunto, aunque sólo de forma parcial, pero en las demás producciones de la arboricultura comarcal (almendra, manzana, etc.) su comercialización está, de modo preferente o absoluto, en manos del sector privado. 


\section{Cooperativismo y comercialización en el sector oleícola}

Tradicionalmente los grandes masos contaban con una almazara propia, en tanto que los pequeños olivicultores se encuadraron en cooperativas de ámbito local, muchas de cuyas almazaras, en particular las de mayor talla, se limitaban a molturar y, como mucho, una vez retirado el aceite para autoconsumo, comercializaban el módico remanente.

Durante la etapa autártica de postguerra la indigencia de los canales comerciales propiciaba una considerable multiplicidad de variedades y aún de usos a los que se destinaban las aceitunas, y ello dentro de unos mercados de ámbito relativamente restringido.

Por entonces casi todo el aceite se consumía en la propia comarca y en algunas poblaciones vecinas. Asimismo había una relativa difusión, por la Foia de Castalla, zona de Biar y Les Valls d'Alcoi, de variedades que, como la cuquello, cornicabra, etc., eran apreciadas para la elaboración de salmueras.

A partir de los años setenta se ha producido una completa mutación de los mercados, lo cual se acompaña de una mayor especialización dentro de la olivicultura, pues ésta tiende a volcarse hacia variedades que, ajustadas al suelo y clima comarcales, se ligan «vocacionalmente» a los nuevos usos y clientelas. Así, en tanto que el fruto de almazara lo demandan en proporción creciente los industriales de Cataluña, las afamadas fábricas conserveras del ramo que se han desarrollado en Alcoi, compran en Sevilla latas o botes de salmuera -con olivas andaluzas y, sobre todo, de Badajoz (Almendralejo, en especial)- para proceder aquí a deshuesarlas y rellenarlas de anchoa y pimiento. De ello resulta la gran paradoja de que mientras buena parte del fruto comarcal halla su destino en Cataluña, la industria alcoyana se nutre de las aceitunas de SW español, y éstas llegan aquí en salmuera, en tanto que la producción local que antaño tenía este uso, ahora es cosecha de verdeo y, por lo común, se envía a la plaza de Alacant para aderezo, bien entendido que su cuantía es irrisoria si se compara con la producción de almazara.

A comienzos de la pasada década, según el GABINETE SIGMA (p. 138), de las 24 cooperativas agrarias censadas en la zona, 21 poseían almazara, existiendo una cifra pareja de almazaras particulares, aunque no todas ellas funcionaban y algunas lo hacían intermitentemente.

Las almazaras cooperativas tenían un ámbito de actuación restringido (un municipio o parte de él) y serios problemas estructurales, derivados de su irrisoria producción global.

La vetustez de los equipos y la exigua dimensión condicionaban unos parcos rendimientos operativos, un exceso de la mano de obra sobre el coste final y una acentuación del detrimento de la calidad, ya menoscabada por el propio descuido cultural en que venía sumido el olivar desde la crisis de finales de los cincuenta.

Tal crisis se ha ido superando a lo largo de la década de los setenta, de forma paulatina, y desde 1980 más decididamente, siendo crucial al efecto 
junto con el alza generalizada de precios en el sector oleícola español, la fuerte demanda que sobre la producción comarcal vienen ejerciendo en medida creciente los industriales catalanes del ámbito de la denominación de origen «Borges Blanques» (Lleida), elaboradores de aceite frutados, quienes aprecian las irreprochables características de los que se extraen de la aceituna alcoyana (cuerpo, baja acidez y buen sabor, aroma y color); también la compran los de Tortosa y Reus (Tarragona).

Ya por el año 1973 (G. SIGMA, pp. 137-138) alrededor del 35\% de la producción olivarera se vendía, sin molturar, a mayoristas catalanes, mediando en la transacción los comisionistas locales, y esas ventas se canalizaban de preferencia, como ocurre hoy, a través de las propias cooperativas. En cuanto al aceite entonces elaborado en la comarca por ellas (el $85^{\circ}$ lo del mismo) o por particulares, cerca del $60 \%$ (el de más calidad) hallaba su destinatario en la clientela catalana, y el sobrante se distribuía entre los almacenistas locales o los de Alacant y València.

La mayoría de las cooperativas se encontraron con que, dados los altos costos y bajo rendimiento de sus pequeñas y anacrónicas almazaras, la resultante era favorable a las operaciones de venta de la aceituna; con dejadez, a menudo, de su vertiente industrializadora, se convirtieron en simples cooperativas «de negociación», supeditadas a los intereses comerciales privados, pues gran parte de su labor se ceñía a facilitar el aprovisionamiento a los oligopolios del sector.

El progresivo incremento de la demanda sirvió de acicate para promover un concierto intercooperativo, el cual se constituyó en 1979. En la primera campaña reunió a 12 cooperativas locales que vendieron en común unas $1.400 \mathrm{Tm}$ de aceituna en fresco y el aceite resultante de molturar otras $600 \mathrm{Tm}$, todo ello por un valor superior a 60 millones de pesetas, obteniendo un superávit de $6 \mathrm{ptas} / \mathrm{kg}$ sobre el precio conseguido por las cooperativas no concertadas (INIGUEZ, p. 61).

Durante las cinco campañas en las que el grupo ha venido funcionando en calidad de concierto, sus prestaciones han sido positivas para los olivicultores, pues al concentrar la oferta y controlar volúmenes suficientes y calidades cada vez más homogéneas (lo que también beneficiaba al comprador), mejoró la capacidad de negociación frente al oligopolio de la demanda, que ha continuado siendo protagonizada en esencia por los envasadores catalanes.

Las almazaras cooperativas que no se habían concertado eran precisamente las poseedoras de una mayor capacidad de molturación; varias de ellas y también las del concierto sostenían una estrategia flexible a lo largo de cada campaña, de tal forma que si los precios de la aceituna eran satisfactorios, la vendían en fresco, y de lo contrario, optaban por molturarla, en especial cuando la temporada de recolección estaba avanzada, ya que entonces el rendimiento en aceite es máximo. Pero esa labor de transformación ha venido siendo lastrada por la obsolescencia de los equipos, si bien unas pocas almazaras los actualizaron parcialmente e incorporaron medios para el prelavado del fruto. 
Llegado el año 1984 dicho grupo se constituyó en una sociedad cooperativa de $2 .^{\circ}$ grado que responde a las siglas SOCAPMA, la cual viene exigiendo el cumplimiento de la obligación inherente a los socios de aportar la totalidad de sus cosechas. Algunas de las cooperativas que antes se incluían en el concierto no se han integrado en la sociedad, que por ahora agrupa a 9 cooperativas locales; cuatro de ellas, las de Planes, Margarida, Benialfaquí y Catamarruc, pertenecen al mismo término municipal, completando el repertorio las de Muro, Benimarfull, Gorga, el Patró y la Vall d'Alcalà (estas dos situadas en el Marquesat de Dénia).

Todas ellas presentan como circunstancia común la carencia de almazara o, lo que es equivalente, la caducidad e inoperancia de la que poseen. La cooperativa de Muro se creó ex profeso antes de formalizarse SOCAPMA, con la finalidad concreta de insertar la olivicultura local (la segunda en importancia de la comarca) en la nueva sociedad que por entonces se gestaba y en la cual Muro tendrá un destacado protagonismo por ubicarse allí la futura almazara comarcal.

Fuera de SOCAPMA quedan una serie de almazaras-cooperativas, como la de Cocentaina (la de mayor capacidad y dinamismo), Beniarrés, Benilloba y otras; el aceite que elaboran es retirado en parte por los socios y el excedente se vende a granel en la propia almazara, siendo también apetecido por los envasadores de Borges Blanques.

Aunque transitoriamente SOCAPMA prosigue el cometido, que ya asumía el concierto, de acopiar la aceituna para negociar su venta en mejores condiciones (obtuvo entre 45 y más de $50 \mathrm{ptas} / \mathrm{kg}$ de liquidación neta al socio en 1985), el objetivo para el que en realidad se creó, y que persigue a corto plazo, es la transformación in situ de toda la producción, haciendo partícipe al socio del consiguiente valor añadido que, por ahora, le sustraen los industriales envasadores.

Para ello dicha sociedad, con las ayudas gestionadas por medio del -en su día- IRYDA (en el marco de la Zona de Ordenación de Explotaciones «Montaña de Alicante»), está erigiendo una moderna macroalmazara, de nivel comarcal. (Entre tanto, el aceite para autoconsumo de los socios lo produce en la única almazara del grupo viable al efecto, la de Benimarfull).

La nueva almazara va a implicar la concentración en un punto de las cosechas de los olivicultores, planteándose con ello el problema de los costos diferenciales del transporte (a compensar mediante subvenciones a los socios perjudicados). Por ende, la elección de su emplazamiento era una cuestión crucial y, en nuestra opinión, está resuelta satisfactoriamente, pues ha recaído en Muro, población que se ubica en el seno de la subárea más olivarera de Les Valls y es accesible por la carretera nacional 340.

En la actualidad este sector cooperativo se ha propuesto demostrar que hay una vía propia, alternativa al sector privado, a través de una política unitaria de marca. Se trata de conseguir una denominación de origen para el aceite comarcal, a cuyo fin se están realizando los estudios pertinentes para homo- 
logarlo. Con una etiqueta de origen como garantía de lanzamiento de unos aceites tipificados, con la calidad y presentación adecuadas, se podría penetrar eficazmente en diversos mercados, cuyo aprovisionamiento estaría avalado por la disponibilidad de una oferta relativamente cuantiosa, que las cooperativas locales, por sí solas, no refrendarían. La unión intercooperativa debe imponerse, no sólo porque a nivel de municipio es difícil encontrar una base territorial suficiente para mantener una almazara en condiciones económicas saneadas, sino también porque, para lograr éstas, deben hacer frente a la instalación y mantenimiento de plantas envasadoras; además, cabe la posibilidad de incorporar las ayudas al consumo al sector almazarero si éste es capaz de constituirse en envasador marquista.

En esta línea de acción, se inscriben también las negociaciones que se mantienen con el ICAV para la firma de un convenio, a fin de comprometerse a abordar de forma coordinada, bajo la supervisión técnica de la Consellería d'Agricultura, toda una serie de mejoras, beneficiándose de las líneas de apoyo institucionales, tal como se está haciendo en el Maestrat y la Plana Alta de Castelló. A su vez en estas comarcas olivareras y en la del Vinalopó se han suscitado promociones del tipo de la concertación y cooperativismo de $2 .^{\circ}$ grado como «efecto demostración» de las que han cuajado de forma pionera en el área alcoyana.

\section{El cooperativismo en el sector de la cereza}

El movimiento asociativo para la comercialización en común de la producción cerecera de la zona norte de la provincia se ha encontrado con dos factores geográficos de signo muy dispar; por una parte, la concentración del cerezo sobre un área continua, a caballo de las comarcas de Alcoi y Dénia, propiciaba una acción comercial conjunta, pero, por otra, la diáspora de los productores en un mosaico de diminutas entidades de población (cerca de la veintena), mal conectadas entre sí, propendía a atomizar toda iniciativa al efecto.

El camino hacia la cooperación, finalmente culminado con éxito, ha sido lento y plagado de obstáculos. Algunas de las múltiples minicooperativas de ámbito local (y orientadas en particular al servicio de almazara) iniciaron ya en los años sesenta tímidos ensayos para la venta de cerezas, con poca fortuna.

En la década siguiente se relanzó esta prestación, de modo que hacia 1976 atañía a todas las cooperativas de la zona, pero cada una concurría a los mercados nacionales en competencia con las demás, manipulando con escasos medios una mercancía muy perecedera y, en gran parte, obtenida de unas variedades autóctonas exentas de calidad suficiente.

Pese a ello, en el quinquenio 1973-77 los precios netos de la cereza se duplicaron respecto a 1972. En este año se efectuó desde Planes el primer escareo exportador, pulsando la plaza de Londres con envíos precarios, que repitieron 
ésta y otras cooperativas en campañas posteriores, y en 1975 sondearon otros mercados -caso de Alemania Federal- utilizando como vector el mercado de origen Mercosegura-Alicante.

Era patente, con todo, la necesidad de vencer el minifundismo cooperativo e integrar un frente común, misión que fue alentada por Extensión Agraria propiciando diversos contactos y un viaje al extremeño Valle del Jerte para estudiar su asociacionismo cerecero. Ello condujo en 1978 a la firma de un concierto intercooperativo por 16 entidades de la zona Alcoi-Dénia, que establecía una gerencia común inicialmente ubicada en Planes (su sede es rotatoria).

Desde entonces los logros han sido muy sustanciales. Se han abaratado los inputs al comprarlos en común, mejorando la estructura varietal de las plantaciones, esmerado la confección de las cerezas y cuidado su normalización y tipificación. (Incluso se propició la apertura de nuevos caminos rurales, mediante el trabajo comunitario.) El precio medio neto obtenido, que en 1977 fue de 27 ptas/kg, pasó a 70 al año siguiente, y ha alcanzado las 205 ptas en 1985.

En consecuencia, alrededor de 1.600 empresarios agrícolas de la zona han incrementado notablemente los ingresos procedentes de sus explotaciones, cuya rentabilidad alcanza cotas sorprendentes.

Recientemente el grupo ha conseguido una serie de realizaciones, de las que espera notorios beneficios a corto plazo. En la campaña de 1983, coincidiendo con una gran cosecha, los tímidos tanteos exportadores de los setenta empezaron a tomar cierta consistencia y alrededor del 15\% de la producción fue colocado en los mercados de Alemania, Gran Bretaña, Noruega, Finlandia, Canadá y Arabia Saudita con resultado positivo.

En 1984 se constituyó en cooperativa de 2. ${ }^{\circ}$ grado, «Cerezas Montaña de Alicante, S.C.L.», y al año siguiente, acogiéndose a subvenciones oficiales (como las citadas en SOCAPMA), se construyeron dos centrales hortofrutícolas, en Benifarfull (700 m²) y en el Patró $\left(800 \mathrm{~m}^{2}\right)$-, en las cuales se pretende centralizar la confección de la cereza. Las cooperativas hoy integradas son 16, de las que 7 -Almudaina, Benialfaquí, Benimarfull, Catamarruc, L'Orxa, Margarida y Planes- pertenecen a la comarca alcoyana y el resto a la dianense.

Se calcula que en conjunto comercializa alrededor de 2,5 ó 3 millones de $\mathrm{kg}$ de cerezas, cifra que fluctúa a tenor de la cosecha. Siguen destinándose preferentemente al mercado interior, donde parece ser que más de la mitad son absorbidas entre la propia provincia -Alacant, Benidorm, Elx, Elda, Orihuela y Alcoi, en particular- y las plazas de Murcia y Cartagena; del resto destacan los mercados de Barcelona y Ciutat de Mallorca (abastecida por avión, desde El Altet) y los sobrantes se expiden a Madrid. Lo habitual es el envío a asentadores de esas plazas, que trabajan por el sistema de comisión.

Las apetencias del cliente se inclinan por las clases tempranas y de mayor tamaño, como la tilagua y la francesa; las primicias son más rentables (en 
1985 a unas 500 ptas $/ \mathrm{kg}$ ) y conforme avanza la temporada la cotización disminuye (200 ptas/kg, a finales de junio). De ahí que las cooperativas liquiden al productor por precio medio diario, pues además, depende de las plazas destinatarias: las mejores suelen ser Barcelona y Mallorca; Murcia da un tono medio, en tanto que Valencia, donde concurre la cereza de la Vall de Sogorb, se inscribe entre las mediocres; en la Costa Blanca alicantina, donde el volumen ofertado es cuantioso, la cotización es algo superior a la media. Para el año actual, los objetivos que se ha planteado la intercooperativa cerecera son, entre otros, los de establecer una sección de crédito, conseguir una licencia de exportación propia y obtener la calificación de A.P.A.

\section{Aspectos de la comercialización en otros sectores de la arboricultura}

El melocotón, entre el cooperativismo y el sector privado.- El melocotonero se cultiva, al igual que el cerezo, en el seno de la agricultura de tipo familiar, en pequeñas propiedades. También el asociacionismo ha cuajado en este caso, si bien con menor intensidad que lo ha hecho el sector cerecero que, a diferencia de éste, cuenta con dos cooperativas de primer grado, las cuales no cubren sino una parte, bien que significativa, de la producción melocotonera.

Dichas cooperativas vienen funcionando desde hace 7 u 8 años y cada una dispone de un almacén frutícola, situados uno en Gorga y otro en Benimarfull. La mayor parte de sus socios son agricultores de ambas localidades, pero también se cuentan en Millena y, más secundariamente, en Balones y Quatretondeta, por lo que puede afirmarse que su ámbito se extiende por gran parte de la Vall de Travadell o «subcomarca del melocotón».

Es un ejemplo más de cooperativas de negociación, pues su sistema operativo consiste en acopiar la fruta y seleccionarla para venderla en el propio almacén a mayoristas y asentadores. Por esta vía se estima grosso modo que comercializan poco menos de dos terceras partes del melocotón comarcal.

El resto se canaliza a través de comerciantes que compran la fruta en el bancal, aunque hay algunos productores que venden directamente en la lonja de Alcoi e incluso hay quien la lleva hasta las de Alacant, Elx y Murcia.

Se trata de una fruta de gran calidad, en general, que obtiene buenas cotizaciones (se liquidó a unas 50 ptas/kg en la pasada campaña). Dada su diversidad varietal, la temporada del melocotón se prolonga desde finales de junio hasta primeros de noviembre, lo cual facilita una comercialización en cierta medida desahogada.

Con todo, la mayor parte de la producción es tardía, y se escalona en dos etapas; la fruta agostenca, al coincidir con el fuerte tirón de la demanda del litoral turístico, se coloca de preferencia en La Marina (Benidorm, en particular), mientras que la cosecha se septiembre-octubre se consume más en Alacant, Alzira, València y otros núcleos urbanos. 
La problemática comercial de las «frutas de los masos»: el manzano.- Dentro del abanico de frutas frescas que produce la comarca, las únicas en que no interviene hoy, ni siquiera parcialmente, alguna modalidad de asociación para la comercialización en común son precisamente aquéllas cuya producción recae básicamente en las explotaciones de mayor dimensión, en particular las de tipo mas.

Sin embargo, hubo un ambicioso intento de encauzar el mercado de esas producciones por la vía del asociacionismo, pero tal experiencia redundó al cabo de unos años en un estrepitoso fracaso. Se trata de la cooperativa agrícola «San Jorge» de Alcoi, puesta en marcha hacia 1968, la cual era conocida como «la dels masos» porque sus fundadores eran titulares de las mayores explotaciones de la zona, con importantes plantaciones de frutales. En 1971 censaba 29 socios, dueños de masos en Alcoi (14), Penáguila (3), otros puntos de la comarca (7), Ibi (3), Banyeres y Sella. Hemos reconocido entre ellos 16 industriales, 7 de profesión liberal y 3 vinculados al comercio y finanzas. En conjunto sus posesiones sumaban más de 60.000 pies de manzanos, más de 20.000 perales, unos 12.000 albaricoqueros, otros tantos ciruelos y cerca de 10.000 melocotoneros.

Funcionó durante unos 8 años como un grupo de negociación, acopiando la producción frutícola propia, la cual, si convenía, se hibernaba en instalaciones privadas de conservación en frío. Pero no hubo un auténtico espíritu asociativo y sí un exceso de protagonismo que abocó a la disolución de la sociedad, mediada ya la década de los setenta.

Esta datación es significativa pues remite el momento en que se cuestiona la viabilidad comercial de la manzana, principal producción de los masos de orientación fruticultora. En efecto, en 1974 se predecía: «la situación actual todavía no es crítica, dado el nivel de precios que alcanza la fruta. La probable presencia en el mercado, en un futuro próximo, de excedentes de producción, agravará sensiblemente el problema» de la rentabilidad (G. SIGMA, p. 151).

La temida coyuntura de superproducción, agravada por la deficiente comercialización, no se hizo de esperar y, con el aumento de los costos, una vez mediada la década los precios resultaron poco remuneradores. Ello salvo alguna ocasional reactivación del mercado, como cuando en 1980 las mermas de cosecha, por las heladas y por el arranque de manzanos en la vecina Villena, y el agotamiento de las reservas de fruto en cámara motivaron en ese otoño un alza de las cotizaciones.

Pero fue un espejismo; desde 1981, coincidiendo con situaciones de superproducción en otras zonas competidoras, los precios de la manzana -al menos en la comarca- han ido en descenso; el intento de sostenerlos mediante el recurso al almacenamiento en cámaras de frío se traducía en costos adicionales y mayores pérdidas.

Con todo, hay quien todavía «cree» en el manzano, en base a que las condiciones ecológicas para el mismo, salvo anomalías, no son desfavorables y sobre todo porque esta manzana de secano, rica en azúcar y de buen sabor, es 
de calidad extraordinaria; casi siempre se ha pagado mejor que el fruto villenense, que es de regadío.

La comarca puede y debe ir hacia una especialización frutícola, por la que hay una vocación ecológica, mientras que, por contra, en el ramo de la cerealicultura -hacia la que vuelven muchos masos- existen en la península muchas zonas que parten con clara ventaja sobre estos valles. La cuestión estriba en obtener la cotización que merece aquella calidad, para lo cual habría que organizar mejor el sistema y los canales de comercialización. Por ahora se ha solucionado el déficit de la red de almacenamiento en frío; si a comienzos de los setenta era inexistente (ya entonces se retenía en cámaras de Villena y de Xátiva el $80 \%$ de la manzana, un $70 \%$ de la pera y la mitad de la ciruela), por contra las instalaciones que hoy funcionan en Agres y en Alcoi cubren con creces las necesidades. En ellas se guarda el remanente no vendido de la manzana cosechada a primeros de otoño, que desde abril o mayo encontrará salida entre los comerciantes fruteros.

La producción local de manzana halla parte de su destino comercial en las ciudades de València y Alacant y el espacio litoral turístico intermedio, bien que en mayor medida se coloca en núcleos urbanos más alejados, entre los que destacan Madrid, Barcelona, Mallorca, Málaga y algunos del norte. En los próximos años es muy probable que las plantaciones de media estación continúen menguando, pudiendo aumentar un poco las de verano, pues presentan menos riesgos climáticos y sus manzanas obtienen mejor precio, aunque tienen el contrapunto de que, por ser de consumo inmediato y volcarse al mercado en breve lapso, quizás lleguen a saturarlo.

En cuanto a los más modestos excedentes de peras y albaricoques se destinan casi todos al área litoral de las provincias de Alacant y de València, mientras que los correspondientes a la ciruela se distribuye de preferencia por los mercados de Madrid y de la zona norte. Estas producciones se venden a través de comerciantes, sobre todo de los que operan en la limítrofe Vall d'Albaida.

La venta de la almendra.- Precisamente, a escasa distancia de la comarca alcoyana, la industria turronera de Xixona absorbe alrededor de 10.000 Tm de almendra en grano, y también la consumen el sector heladero, de gran arraigo en la provincia, las fábricas de chocolate de La Vila Joiosa, las de peladillas de la propia Alcoi y las tostadoras y elaboradoras de frutos secos. En el área de Xixona-Alacant radican importantes firmas comerciales que la convierten en uno de los principales centros exportadores de almendras, junto con Reus.

La cadena clásica de comercialización es: agricultor-corredor -almacenista en origen (descascarador)- industrial y/o exportador; éste es un canal-tipo simplificado, que a menudo se complica al intervenir otros agentes o al integrarse verticalmente ciertos eslabones. Por ejemplo, en la provincia se detecta una tendencia por parte del industrial a asumir la fase del descascarado mediante la adquisición de las instalaciones correspondientes o su participación en ellas, al objeto de asegurarse un aprovisionamiento en cuantía y en ca- 
lidad. En Almudaina (Vall de Planes) radica, precisamente, una de las principales descascaradoras de la provincia, propiedad de una firma turronera.

El asociacionismo agrario tiene entidad en este sector. En 1978 se creó en Castalla, localidad muy próxima a Alcoi, la sociedad Cooperativa «Montaña-Vinalopó» (calificada como A.P.A.) para descascarar y comercializar la almendra de unos 900 socios repartidos en 42 municipios (entre ellos, varios de Les Valls). En el descascarado su movimiento es notoriamente recesivo, pues en 1984 pasó por su planta, muy infrautilizada, poco mas de 1/3 del volumen manipulado en 1981; la venta del fruto en grano la efectúa a través de la cooperativa de $2 .^{\circ}$ grado «Almendras de España».

Algunas cooperativas de Les Valls, especializadas en otras producciones, como es la de Cocentaina, suelen acopiar la almendra que aportan sus socios para la venta conjunta a los comerciantes a su envío a descascaradoras particulares, entre las que se cuenta las de Almudaina, liquidando después a tenor del rendimiento medio.*

\section{!}

* Gran parte de la información que ha servido de base para elaborar este estudio se debe al trabajo de campo y a la labor de encuesta y entrevistas personales con empresarios y con técnicos del sector agrario, a quienes expresamos nuestro agradecimiento más sincero. Varias de estas personas las citamos en una publicación sobre las estructuras agrarias de la comarca. En esta ocasión cabe mencionar expresamente la valiosa ayuda prestada por el Servicio de Extensión Agraria en las personas de F. Sala Magraner, J. A. Amorós Silvestre y F. Such Martí, así como por Ginés Llorca, del Servicio Territorial de Agricultura, José A. Poveda, de UTECO, y A. Lloréns Campos y Francisco Figuerola, del sector cooperativo.

\section{BIBLIOGRAFÍA}

COSTA MAS, José: «Explotaciones agrarias de Les Valls d'Alcoi: el mas, la empresa familiar y el agricultor alternante», Investigaciones Geográficas, núm. 3, Universidad de Alicante, 1985, pp. 83-115.

GABINETE SIGMA: La economía de Alcoy y comarca, Caja de Ahorros y Monte de Piedad de Alcoy, $1974,400 \mathrm{pp}$.

INIGUEZ MONTERDE, Arturo: «Las Sociedades Cooperativas para la elaboración del aceite de oliva», El Campo, núm. 97, Madrid, Banco de Bilbao, 1985, pp. 59-62.

PREVASA: Situación actual, problemas y perspectivas de las comarcas valencianas. L Alcoià, Caja de Ahorros de Valencia, 1972, 73 pp.

VALLES, Ismael: Indústria tèxtil i societat a la Regió Alcoi-Ontinyent, València, Diputació Provincial, 1986. 